\title{
ANALISIS NON VALUE ADDED ACTIVITY MELALUI PENERAPAN ACTIVITY BASED MANAGEMENT UNTUK MENINGKATKAN EFISIENSI PT. INDOFOOD CBP SUKSES MAKMUR, Tbk CABANG BITUNG
}

\author{
${\text { Reika Fichristika Kutika }{ }^{1} \text {, David. P.E. Saerang }}^{2}$, Natalia Y.T Gerungai ${ }^{3}$ \\ 1,2,3 Jurusan Akuntansi, Fakultas Ekonomi dan Bisnis, Universitas Sam Ratulangi, Jl. Kampus Bahu, Manado, \\ 95115, Indonesia \\ E-mail : kutikareika@gmail.com
}

\begin{abstract}
Nowadays, the changes that occur in the business environment creates competitiveness between companies in terms of seizing the market. For these companies, one of the way to achieve excellence is by being constantly focused on improving their processes and activities, paying attention to quality, flexibility and cost efficiency. Along with the competition of manufacturing companies that occur these days, PT. Indofood CBP Sukses Makmur, Tbk Bitung Branch must be able to manage its activities effectively and efficiently in order to achieve competitive advantage. Ergo, what companies need to do to improve its efficiency is by managing the activities that occur without reducing the quality of their products provided to customers. This study aims to find out how the application of activity based management at PT. Indofood CBP Sukses Makmur, Tbk Bitung Branch and how non value added activity can improve the efficiency of the company. The data analyze used descriptive analysis with qualitative approach and activity based management method. Based on the research, it is indicated that some non value-added activities are still going on, and by applying the activity-based management method, there is no added-value by the company's reduction cost. By using activity-based management method, the total overhead cost of the factory is reduced by $R p 2,384,750,669,84$ or $20,30 \%$.
\end{abstract}

Keyword: Activity Based Management, Non Value Added Activity, Efficiency

\section{PENDAHULUAN}

Di masa sekarang ini, perubahan yang terjadi di lingkungan bisnis membuat persaingan antar perusahaan dalam merebut pasar menjadi sangat kompetitif. Aktivitas menjadi hal penting dalam melakukan pengendalian dan penilaian performance lingkungan yang dinamis. Pengelolaan aktivitas (activity management) merupakan suatu proses pengidentifikasian aktivitas yang dijalankan oleh perusahaan, penentuan nilainya bagi perusahaan, pemilihan serta pelaksanaan aktivitas yang menambah nilai bagi konsumen, mengidentifikasikan atau menghilangkan semua aktivitas tak bernilai tambah dan memperbaiki aktivitas bernilai tambah sehingga menghasilkan penurunan biaya (Sitorus, Poputra, dan Runtu, 2014:1002). Melihat dari pentingnya pengelolaan aktivitas perusahaan maka setiap perusahaan perlu menganalisis dan mengidentifikasi aktivitas-aktivitas yang terjadi di perusahaan.

Aktivitas-aktivitas tersebut dapat dibedakan menjadi dua, yaitu aktivitas bernilai tambah (value added activity) dan aktivitas tidak bernilai tambah (non value added activity). Aktivitas bernilai tambah/ value added activity adalah aktivitas yang dibutuhkan atau diharuskan untuk melaksanakan bisnis dan menambah nilai produk, sedangkan aktivitas tidak bernilai tambah/ non value added activity adalah aktivitas yang tidak perlu atau aktivitasaktivitas yang perlu namun tidak efisien dan dapat disempurnakan dan tidak menambah nilai produk. PT. Indofood CBP Sukses Makmur, Tbk cabang Bitung merupakan divisi pembuatan mie instan (noodle division). PT Indofood CBP Sukses Makmur, Tbk cabang Bitung adalah perusahaan manufaktur yang memproduksi beberapa produk mie instan antara lain indomie, 
supermi, sarimi, sakura dan pop mie. PT. Indofood CBP Sukses Makmur, Tbk cabang Bitung memiliki siklus produksi yang cukup panjang mulai dari proses penerimaan bahan baku, pemilihan bahan baku, pemrosesan bahan baku, pengolahan, pengemasan, sampai penilaian barang jadi yang mana produk tersebut layak dijual atau tidak layak dijual dan juga aktivitas operasional perusahaan lainnya. Dalam menjalankan kegiatan produksinya perusahaan perlu memperhatikan mengenai aktivitas-aktivitas yang terjadi dalam proses produksi. Untuk itu yang perlu dilakukan oleh perusahaan guna meningkatkan efisiensinya yaitu dengan melakukan identifikasi terhadap aktivitas-aktivitas produksi yang terjadi. Dalam mengelola aktivitas tersebut dinamakan activity based management atau manajemen berdasarkan aktivitas. Metode manajemen berdasarkan aktivitas merupakan metode yang mengelola suatu aktivitas untuk meningkatkan value (nilai) yang diterima oleh pelanggan dan juga untuk meningkatkan laba melalui value tersebut.

\section{TINJAUAN PUSTAKA}

\subsection{Sistem Akuntansi Manajemen}

Wirjono (2013:37) mendefinisikan sistem akuntansi manajemen merupakan sistem yang didesain secara formal untuk menyediakan informasi yang diperlukan oleh manajer dalam rangka mendukung pengambilan keputusan dan evaluasi aktivitas manajerial. Sistem akuntansi manajemen berfokus pada proses yang dideskripsikan oleh aktivitas-aktivitas, seperti pengumpulan, pengukuran, penyimpanan, analisis, pelaporan dan pengelolaan informasi.

\subsection{Activity Based Management (ABM)}

Hansen dan Mowen (2012:224) menjelaskan bahwa manajemen berbasis aktivitas atau activity based management merupakan suatu keseluruhan sistem yang terintegrasi dan berfokus pada perhatian manajemen pada berbagai aktivitas dengan tujuan untuk meningkatkan value bagi pelanggan dan laba yang dicapai dengan mewujudkan value tersebut. Mulyadi (2013:431) mendefinisikan ABM merupakan pendekatan manajemen yang berpusat pada pengelol,aan aktivitas untuk melakukan perbaikan berkelanjutan terhadap nilai yang dihasilkan untuk pelanggan dan peningkatan laba dari penyedia value tersebut.

\subsubsection{Manfaat Dan Keunggulan Activity Based Management}

Blocher, dkk (2011), activity based management memiliki beberapa manfaat, yaitu sebagai berikut:

1.Melakukan perbaikan operasi

2.Mengurangi biaya

3.Meningkatkan nilai bagi suatu perusahaan

Blocher, dkk (2011) menjelaskan 2 keunggulan ABM, yaitu (1) Mengkur efektivitas proses dan aktivitas bisnis kunci serta mengidentifikasikannya dengan tujuan untuk menurunkan biaya dan meningkatkan nilai bagi pelanggan. (2) Memperbaiki fokus manajemen

\subsubsection{Dimensi Activity Based Management}

Dimensi bertujuan untuk pengurangan biaya. Dimensi juga menyediakan kemampuan untuk terlibat dan mengukur peningkatan berkelanjutan. Activity Based Management memiliki dua dimensi, yakni dimensi biaya dan dimensi proses. Dimensi biaya adalah dimensi dalam ABM yang bertujuan untuk menyempurnakan keakuratan penelusuran biaya pada objek-objek biaya, sedangkan dimensi proses adalah dimensi ABM yang memberikan kemampuan untuk melakukan dan mengukur perbaikan berkelanjutan.

\subsection{Aktivitas}

Blocher, dkk (2011:21) menjelaskan bahwa aktivitas sangat berperan penting dalam melakukan pembebanan biaya ke objek biaya lainnya dan merupakan dasar dari sistem akuntansi manajemen kontemporer. Dalam konsep ABM, aktivitas merupakan pusat 
perhatian dalam pengendalian manajemen, karena dengan mengendalikan aktivitas, manajemen dapat mengendalikan organisasi secara keseluruhan.

\subsection{Analisis Aktivitas}

Hansen dan Mowen (2009:237), menyatakan bahwa analisis aktivitas merupakan proses pengidentifikasian, penjelasan, dan pengevaluasian aktivitas yang dilakukan perusahaan. Atikson (2011:53) menjelaskan secara spesifik analisis aktivitas dapat dilaksanakan melalui empat tahap, yaitu: identifikasi tujuan proses, pencatatan aktivitas, klasifikasi dan perbaikan berkelanjutan.

\subsection{Aktivitas Bernilai Tambah (Value Added Activity)}

Hansen dan Mowen (2012:237), mendefinisikan bahwa aktivitas bernilai tambah (value added activity) adalah aktivitas-aktivitas yang perlu untuk dipertahankan dan merupakan aktivitas yang dibutuhkan agar dapat bertahan dalam bisnis. Aktivitas bernilai tambah (value added activities) adalah aktivitas yang memberikan value kepada customer (Riwayadi, 2014:31). Blocher, dkk (2011), menyebutkan bahwa terdapat 2 (dua) macam aktivitas bernilai tambah, yaitu: (1) Aktivitas yang diperlukan (required activity), (2) Aktivitas diskrusioner (discretionary activity).

\subsection{Aktivitas Tidak Bernilai Tambah (Non Value Added Activity)}

Hansen dan Mowen (2012:239), mendefinisikan non value added activity merupakan aktivitas yang tidak memberikan kontribusi terhadap nilai konsumen atau terhadap kebutuhan organisasi. Siregar et al (2013:258), berpendapat bahwa aktivitas tidak bernilai tambah adalah aktivitas yang memakan waktu, sumber daya, atau tempat tetapi hanya memberikan sedikit nilai tambah bagi kepuasan pelanggan atau bahkan sama sekali tidak memberikan value adeed.

\subsection{Efisiensi}

Fahmi (2012:83), mendefinisikan efisiensi adalah pengukuran kinerja yang melihat dari segi pengerjaan sesuai dengan waktu yang telah direncanakan, bahkan akan lebih baik jika bisa dilakukan penghematan secara lebih intensif.

\subsection{Penelitian Terdahulu}

Penelitian ini mengacu pada penelitian yang dilakukan oleh Kalonio (2017) dengan judul Penerapan Manajemen Berbasis Aktivitas Untuk Meningkatkan Efisiensi Biaya Pada Whiz Prime Hotel. Penelitian ini bertujuan untuk mengetahui bagaimana pelaksanaan manajemen berbasis aktivitas pada industry jasa untuk meningkatkan efisiensi biaya melalui pengidentifikasian aktivitas tidak bernilai tambah. Data yang digunakan berasal dari hasil studi pustaka, observasi dan wawancara pada objek penelitian.

\section{METODE PENELITIAN}

\subsection{Jenis Penelitian}

Penelitian ini dilakukan pada departemen produksi PT. Indofood CBP Sukses Makmur, Tbk Cabang Bitung. Penelitian ini bersifat penelitian kualitatif deskriptif yang bertujuan untuk mendeskripsikan apa-apa yang saat ini berlaku. Penelitian ini dilakukan dengan cara mengidentifikasi aktivitas-aktivitas yang ada di depertemen produksi kemudian mengklasifikasikan aktivitas tersebut menjadi dua bagian yaitu value added activity dan non value added activity. Aktivitas tidak bernilai tambah akan dieliminasi atau digabungkan dengan aktivitas yang sejenis sehingga biaya tidak bernilai tambah yang muncul dari aktivitas tidak bernilai tambah dapat di kurangi jumlahnya. Data yang digunakan yaitu data kuantitatif berupa laporan biaya produksi tahun 2016 dan laporan biaya aktivitas serta data kualitatif yaitu sejarah, aktivitas produksi dan sarana prasarana perusahaan. 


\subsection{Waktu dan Tempat Penelitian}

Penelitian dilakukan pada PT. Indofood CBP Sukses Makmur, Tbk Cabang Bitung yang berlokasi di jalan Walanda Maramis Madidir Weru lingkungan I Pakadoodan Maesa Kota Bitung Provinsi Sulawasi Utara. Penelitian ini dilaksanakan selama bulan Maret-April 2018 .

\subsection{Prosedur Penelitian}

Menentukan rumusan masalah, merumuskan masalah penelitian, mencari informasi yang mendukung penelitian, menentukan metode penelitian, memberikan saran, membuat kesimpulan.

\subsection{Metode Analisis}

Metode analisis yang digunakan dalam penulisan ini adalah metode deskriptif. Sugiyono (2011:21), menjelaskan bahwa metode analisis deskriptif adalah metode yang digunakan untuk menggambarkan atau menganalisis suatu hasil penelitian namun tidak digunakan untuk menggunakan kesimpulan yang lebih luas.

\section{HASIL PENELITIAN DAN PEMBAHASAN}

\subsection{Hasil Penelitian}

Data biaya produksi tahun 2016 PT. Indofood CBP Sukses Makmur, Tbk cabang Bitung dapat dilihat pada tabel dibawah ini:

Tabel 4.1

PT. Indofood CBP Sukses Makmur, Tbk cabang Bitung Realisasi Biaya Produksi Tahun 2016

\begin{tabular}{|c|c|}
\hline Keterangan & Jumlah (Rp) \\
\hline Biaya Bahan Baku Langsung & $4,760,352,000.00$ \\
\hline Biaya Tenaga Kerja Langsung & $6,342,788,053.00$ \\
\hline Biaya Overhead Pabrik & $11,749,749,299.76$ \\
\hline Total Biaya Produksi & $22,852,889,352.76$ \\
\hline
\end{tabular}

Sumber: PT. Indofood CBP Sukses Makmur, Tbk cabang Bitung.

Tabel 4.2

Identifikasi Aktivitas

\begin{tabular}{|c|ll|}
\hline Bagian & \multicolumn{1}{|c|}{ Aktivitas Produksi } \\
\hline Persiapan & 1. & Menerima tepung dengan angkutan truck \\
& 2. & Penyeleksian tepung oleh BPDQC (Branch Process Development and \\
& Quality Control Manager) \\
& 3. & Mengelompokkan tepung sesuai kode pengelompokan \\
& 4. & Menyimpan tepung di gudang khusus tepung \\
& 5. & Mengangkut tepung ke screw conveyor \\
& 6. & Melaksanakan proses pengayakan tepung \\
\hline Pengolahan & 1. & Melaksanakan proses pencampuran dan pengadukan tepung, air dan alkali \\
& 2. & Melaksanakan proses pengepresan \\
& 3. & Melaksanakan proses pengukusan \\
& 4. & Melaksanakan proses pemotongan \\
& 5. & Melaksanakan proses penggorengan \\
& 6. & Melaksanakan proses pendinginan \\
& 7. & Perbaikan dan pemeliharaan mesin pengolahan \\
\hline Penyelesaian & 1. & Pengecekan kelengkapan bumbu, minyak sauce dan solid ingredient secara \\
& 2. manual \\
& 2. & dengecekan kelengkapan bumbu, minyak sauce dan solid ingredient \\
& 3. & Pengemasan/ packing \\
& 4. & Menyimpan barang jadi ke gudang khusus barang jadi \\
\hline
\end{tabular}

Sumber: Data diolah 
Setelah diidentifikasi setiap aktivitas yang ada pada tabel 4.2 selanjutnya dilakukan analisis aktivitas.

1. Menerima Tepung dengan angkutan truck

Aktivitas ini merupakan aktivitas bernilai tambah. Hal ini disebabkan karena aktivitas ini merupakan awal perusahaan untuk mendapatkan bahan baku tepung. Jika aktivitas ini dihilangkan, maka perusahaan tidak bisa melakukan proses produksi karena ketiadaan bahan baku.

2. Penyeleksian Tepung oleh BPDQC (Branch Process Development and Quality Control Manager)

Aktivitas ini merupakan aktivitas bernilai tambah. Hal ini disebabkan karena penyeleksian tepung dilakukan untuk melihat apakah dalam keadaan fisik tepung masih utuh dan tidak tercemar dan juga apakah kondisi truck masih dalam kondisi tersegel serta penyeleksian tepung juga bertujuan agar produk yang dihasilkan nanti berkualitas.

3. Mengelompokkan tepung sesuai kode pengelompokkan

Aktivitas ini merupakan aktivitas bernilai tambah, karena aktivitas ini dilakukan agar sistem FIFO dapat berjalan dengan baik. Tepung yang masuk lebih awal akan diletakan pada kode yang telah ditetapkan agar pada saat pengambilan tepung dapat diketahui mana yang masuk lebih awal.

4. Menyimpan tepung digudang

Aktivitas ini merupakan aktivitas tidak bernilai tambah, karena tidak memberikan perubahan dan penyimpanan bahan baku tepung yang terlalu lama akan mengurangi kualitas produk yang akan dihasilkan akibat terlalu lama waktu penyimpanan.

5. Mengangkut tepung ke screw conveyor.

Aktivitas ini merupakan aktivitas bernilai tambah. Hal ini disebabkan karena mengangkut tepung ke screw conveyor merupakan awal proses produksi akan dilangsungkan.

6. Melaksanakan proses pengayakan tepung

Aktivitas ini merupakan aktivitas bernilai tambah, karena aktivitas ini bertujuan untuk memisahkan tepung dari kutu dan kotoran-kotoran lain yang ada di tepung.

7. Melaksanakan proses pemcampuran tepung, air dan alkali.

Aktivitas ini merupakan aktivitas berniali tambah, karena aktivitas ini betujuan untuk membentuk adonan yang cukup kadar air dan mempunyai struktur gluten yang dapat membentuk lembaran adonan yang baik pada proses pengepresan nantinya.

8. Melaksanakan proses pengepresan.

Aktivitas ini merupakan aktivitas bernilai tambah, tujuan aktivitas ini untuk membentuk struktur net gluten dengan arah yang sama secara merata sehingga lembar adonan menjadi lembut dan elastic. Kemudian dipotong menjadi untaian mie dan dibentuk menjadi bergelombang dan dikelompokkan dalam beberapa jalur.

9. Melaksanakan proses pengukusan

Aktivitas ini merupakan aktivitas bernilai tambah. Hal ini dilakukan untuk memasak mie mentah menjadi mie masak dengan fisik yang solid/ tetap.

10. Melaksanakan proses pemotongan

Aktivitas ini merupakan aktivitas bernilai tambah, karena merupakan proses memotong lajur mie pada ukuran tertentu, melipat dua bagian sama panjang, kemudian mendistribusikannya ke mangkok penggorengan.

11. Melaksanakan proses penggorengan

Aktivitas ini merupakan aktivitas bernilai tambah, tujuannya mengurangi kadar air dalam mie dan pemantapan pati tergelatinisasi. Kadar air mie setelah penggorengan adalah mks $3,5 \%$ sehingga mie menjadi matang kaku dan awet.

12. Melaksanakan proses pendinginan

Aktivitas ini merupakan aktivitas bernilai tambah, karena bertujuan untuk mendinginkan 
mi panas yang keluar dari proses penggorengan hingga diperoleh suhu mendekati suhu kamar 25-300 derajat sebelum dikemas dengan etiket.

13. Perbaikan dan pemeliharaan mesin pengolahan

Aktivitas ini merupakan aktivitas bernilai tambah, karena memungkinkan terjadinya perubahan keadaan. Jika terjadi kerusakan mesin tentunya akan menghambat proses produksi yang sementara berlangsung dan menyababkan aktivitas selanjutnya tidak dapat dilakukan.

14. Pengecekan kelengkapan bumbu, minyak sauce dan solid ingredient secara manual Akvitas ini merupakan bernilai tambah, karena aktivitas ini bertujuan agar pada saat proses pengemasan etiket mie sudah terisi lengkap dengan bumbu, minyak sauce dan solid ingredient.

15. Pengecekan kelengkapan bumbu, minyak sauce dan solid ingredient dengan mesin rejector

Aktivitas ini merupakan aktivitas tidak bernilai tambah, karena aktivitas ini sudah dilakukan secara manual. Tujuan aktivitas ini untuk mengecek kelengkapan bumbu, minyak sauce dan solid ingredient.

16. Pengemasan/ Packing

Aktivitas ini merupakan aktivitas bernilai tambah, karena merupakan aktivitas membungkus mie, bumbu dan minyak sauce dan solid ingredient dengan menggunakan etiket yang dapat melindungi mie dari kemungkinan-kemungkinan tercemar atau rusak, sehingga mie tidak mengalami penurunan kualitas sampai di konsumen.

17. Menyimpan barang jadi ke gudang khusus barang jadi

Aktivitas ini merupakan aktivitas tidak bernilai tambah, karena aktivitas ini tidak menimbulkan perubahan dan penyimpanan barang jadi yang terlalu lama digudang akan mengurangi kualitas produk akibat dari lamanya waktu penyimpanan.

\section{Analisis Pemicu Biaya}

Setelah dilakukan pembagian aktivitas berdasarkan value added activity dan non value added activity, selanjutnya yaitu melakukan analisis pemicu biaya. Analisis pemicu biaya perlu dilakukan dalam upaya untuk mengidentifikasi faktor-faktor penyebab timbulnya biaya aktivitas dari value added activity dan non value added activity. Untuk mengetahui apa saja pemicu biaya yang menyebabkan terjadinya biaya dapat dilihat pada tabel 4.3 berikut ini:

\section{Tabel 4.3}

PT. Indofood CBP Sukses Makmur, Tbk cabang Bitung

Pengukuran Aktivitas

\begin{tabular}{|l|l|}
\hline \multicolumn{1}{|c|}{ Biaya Aktivitas } & \multicolumn{1}{c|}{ Pemicu Biaya } \\
\hline Biaya Bahan Pembantu & Pembabanan Langsung \\
\hline Biaya Tenaga Kerja Tidak Langsung & Jumlah TKTL \\
\hline Biaya Pemeliharaan Mesin \& Peralatan & Pembebanan Langsung \\
\hline Biaya Air & Jumlah Pemakaian Air \\
\hline Biaya Listrik & Jumlah Kilowatt Hours \\
\hline Biaya Penyimpanan Barang Jadi di Gudang & Pembebanan Langsung \\
\hline
\end{tabular}

Sumber: Data diolah

Berikut ini disajikan biaya overhead pabrik setiap aktivitas sebelum eliminasi aktivitas tidak bernilai tambah: 


\begin{tabular}{|c|c|c|}
\hline \multicolumn{3}{|c|}{$\begin{array}{c}\text { Tabel } 4.4 \\
\text { PT. Indofood CBP Sukses Makmur, Tbk cabang Bitung } \\
\text { Biaya Overhead Pabrik Setiap Aktivitas } \\
\text { Sebelum Eliminasi Non Value Added Activity }\end{array}$} \\
\hline No. & Aktivitas & Biaya Aktivitas (Rp) \\
\hline 1 & Menerima tepung dengan angkutan truck & $396,716,384.20$ \\
\hline 2 & $\begin{array}{c}\text { Penyeleksian tepung oleh BPDQC (Branch Process } \\
\text { Development and Quality Control Manager) }\end{array}$ & $220,498,726.12$ \\
\hline 3 & Mengelompokkan tepung sesuai kode pengelompokan & $588,374,691.39$ \\
\hline 4 & Menyimpan tepung di gudang khusus tepung & $583,746,910.39$ \\
\hline 5 & Mengangkut tepung ke screw conveyor & $220,498,726.12$ \\
\hline 6 & Melaksanakan proses pengayakan tepung & $796,716,384.20$ \\
\hline 7 & $\begin{array}{l}\text { Melaksanakan proses pencampuran dan pengadukan } \\
\text { tepung, air, dan alkali }\end{array}$ & $889,716,384.20$ \\
\hline 8 & Melakukan proses pengepresan & $783,746,910.39$ \\
\hline 9 & Melakukan proses pengukusan & $650,489,726.12$ \\
\hline 10 & Melakukan proses pemotongan & $642,220,216.17$ \\
\hline No & Aktivitas & Biaya Aktivitas (Rp) \\
\hline 11 & Melakukan proses penggorengan & $683,039,910.46$ \\
\hline 12 & Melakukan proses pendinginan & $625,767,497.52$ \\
\hline 13 & Perbaikan dan pemeliharaan mesin pengolahan & $883,649,467.93$ \\
\hline 14 & $\begin{array}{l}\text { Pengecekan kelengkapan bumbu, minyak bumbu dan } \\
\text { solid ingredient }\end{array}$ & $986,684,761.20$ \\
\hline 15 & $\begin{array}{l}\text { Penyeleksian kelengkapan bumbu, minyak suace dan } \\
\text { solid ingredient dengan menggunakan mesin rejector }\end{array}$ & $820,726,849.21$ \\
\hline 16 & Pengemasan/ Packing & $996,878,843.90$ \\
\hline 17 & Menyimpan barang jadi ke gudang khusus barang jadi & $980,276,910.24$ \\
\hline & Total & $11,749,749,299.76$ \\
\hline
\end{tabular}

Sumber: Data diolah

\section{Pengukuran Kinerja Aktivitas}

Pada tabel 4.4 ditampilkan jumlah-jumlah biaya berdasarkan analisis aktivitas yaitu aktivitas bernilai tambah (value added activity) dan aktivitas tidak bernilai tambah (non value added activity). Setelah itu aktivitas yang tergolong dalam aktivitas tidak bernilai tambah akan di eliminasi sehingga bisa terjadi pengurangan biaya. Untuk lebih jelasnya dapat dilihat pada tabel dibawah ini: 


\begin{tabular}{|c|c|c|c|c|}
\hline \multicolumn{5}{|c|}{$\begin{array}{c}\text { Tabel } 4.5 \\
\text { PT. Indofood CBP Sukses Makmur, Tbk Cabang Bitung } \\
\text { Laporan Value Added Cost dan Non Value Added Cost Tahun } 2016\end{array}$} \\
\hline No. & Aktivitas & Value Added & $\begin{array}{l}\text { Yang Dapat di } \\
\text { Hilangkan }\end{array}$ & Biaya Aktivitas (Rp) \\
\hline 1 & Menerima tepung dengan angkutan truck & $396,716,384.20$ & & $396,716,384.20$ \\
\hline 2 & $\begin{array}{l}\text { Penyeleksian tepung oleh BPDQC (Branch Process } \\
\text { Development and Quality Control Manager) }\end{array}$ & $220,498,726.12$ & & $220,498,726.12$ \\
\hline 3 & Mengelompokkan tepung sesuai kode pengelompokan & $588,374,691.39$ & & $588,374,691.39$ \\
\hline 4 & Menyimpan tepung di gudang khusus tepung & & $583,746,910.39$ & $583,746,910.39$ \\
\hline 5 & Mengangkut tepung ke screw conveyor & $220,498,726.12$ & & $220,498,726.12$ \\
\hline 6 & Melaksanakan proses pengayakan tepung & $796,716,384.20$ & & $796,716,384.20$ \\
\hline 7 & $\begin{array}{l}\text { Melaksanakan proses pencampuran dan pengadukan } \\
\text { tepung, air, dan alkali }\end{array}$ & $889,716,384.20$ & & $889,716,384.20$ \\
\hline 8 & Melakukan proses pengepresan & $783,746,910.39$ & & $783,746,910.39$ \\
\hline 9 & Melakukan proses pengukusan & $650,489,726.12$ & & $650,489,726.12$ \\
\hline 10 & Melakukan proses pemotongan & $642,220,216.17$ & & $642,220,216.17$ \\
\hline 11 & Melakukan proses penggorengan & $683,039,910.46$ & & $683,039,910.46$ \\
\hline 12 & Melakukan proses pendinginan & $625,767,497.52$ & & $625,767,497.52$ \\
\hline 13 & Perbaikan dan pemeliharaan mesin pengolahan & $883,649,467.93$ & & $883,649,467.93$ \\
\hline 14 & $\begin{array}{l}\text { Pengecekan kelengkapan bumbu, minyak bumbu dan solid } \\
\text { ingredient }\end{array}$ & $986,684,761.20$ & & $986,684,761.20$ \\
\hline 15 & $\begin{array}{l}\begin{array}{l}\text { Penyeleksian kelengkapan bumbu, minyak bumbu dan } \\
\text { solid ingredient } \text { dengan menggunakan mesin rejector }\end{array} \\
\end{array}$ & & $820,726,849.21$ & $820,726,849.21$ \\
\hline 16 & Pengemasan/ Packing & $996,878,843.90$ & & $996,878,843.90$ \\
\hline 17 & Menyimpan barang jadi ke gudang khusus barang jadi & & $980,276,910.24$ & $980,276,910.24$ \\
\hline & Total & $9,364,998,629.92$ & $2,384,750,669.84$ & $11,749,749,299.76$ \\
\hline & Persentase (\%) & $79.70 \%$ & $20.30 \%$ & $100.00 \%$ \\
\hline
\end{tabular}

Sumber: Data diolah

Dari tabel 4.5 dapat dilihat adanya biaya bernilai tambah dan biaya tidak bernilai tambah untuk masing-masing aktivitas proses produksi PT. Indofood CBP Sukses Makmur, Tbk cabang Bitung. Dari hasil laporan biaya bernilai tambah dan biaya tidak bernilai tambah dapat diketahui. Biaya aktivitas tidak bernilai tambah yang akan dieliminasi sebesar Rp 2,384,750,669.84 atau sebesar 20,30\%. Untuk itu diperlukan upaya dari pihak manajemen untuk mengeliminasi aktivitas-aktivitas tidak bernilai tambah, agar efisiensi perusahaan dalam hal ini efisiensi biaya produksi dapat tercapai. Setelah diketahui aktivitas apa saja yang dapat dieliminasi kemudian akan dianalisis aktivitas tidak bernilai tambah tersebut.

\section{Analisis Non Value Added Activity}

Berdasarkan konsep Activity Based Management (ABM), aktivitas-aktivitas yang tidak bernilai tambah harus dikurangi atau dieliminasi. Dari pembahasan aktivitas-aktivitas yang terjadi pada proses produksi berlangsung, berikut ini akan dianalisis aktivitas yang tidak bernilai tambah yang terjadi pada PT. Indofood CBP Sukses Makmur, Tbk cabang Bitung: 
a. Menyimpan tepung digudang khusus tepung

Aktivitas ini dilakukan karena perusahaan memproduksi barang jadi terlalu banyak setiap hari sehingga membutuhkan stok tepung yang banyak. Penyimpanan tepung dilakukan agar stok selalu tersedia saat dibutuhkan. Aktivitas ini tidak bernilai tambah, karena menimbulkan perubahan tetapi menyebabkan timbulnya biaya penimbunan tepung dan pembersihan gudang.

b. Pengecekan kelengkapan bumbu, minyak bumbu dan solid ingredient dengan menggunakan mesin rejector

Aktivitas ini dilakukan untuk mengecek apakah mie sudah terisi bumbu, minyak sauce dan solid ingredient ataukah ada mie yang tidak terisi bumbu. Aktivitas ini dapat dikategorikan dalam aktivitas tidak bernilai tambah, karena aktivitas ini sudah dilakukan secara manual.

c. Menyimpan barang jadi ke gudang khusus barang jadi

Aktivitas ini dilakukan karena perusahaan memproduksi barang jadi terlaku banyak dengan tujuan agar tidak terjadi kehabisan stok sehingga perusahaan tidak segera mengirim barang jadi ke pelanggan tetapi disimpan sementara di gudang. Aktivitas ini tidak bernilai tambah karena menimbulkan perubahan tetapi menyebabkan timbulnya biaya penimbunan mie.

Dari hasil pengeliminasian aktivitas tidak bernilai tambah tersebut, maka biaya aktivitas yang terjadi pada bagian produksi tentu saja akan berkurang, seperti yang terlihat pada tabel 4.6 dibawah ini yang menunjukan biaya aktivitas setelah eliminasi aktivitas-aktivitas yang tidak bernilai tambah.

Tabel 4.6

PT. Indofood CBP Sukses Makmur, Tbk Cabang Bitung Biaya Overhead Pabrik Setelah Eliminasi Aktivitas

\begin{tabular}{|l|l|c|}
\hline No. & Aktivitas & Biaya Aktivitas (Rp) \\
\hline 1 & Menerima tepung dengan angkutan truck & $396,716,384.20$ \\
\hline 2 & $\begin{array}{l}\text { Penyeleksian tepung oleh BPDQC (Branch Process Development and } \\
\text { Quality Control Manager) }\end{array}$ & $220,498,726.12$ \\
\hline 3 & Mengelompokkan tepung sesuai kode pengelompokan & $588,374,691.39$ \\
\hline 4 & Menyimpan tepung di gudang khusus tepung & $220,498,726.12$ \\
\hline 5 & Mengangkut tepung ke screw conveyor & $796,716,384.20$ \\
\hline 6 & Melaksanakan proses pengayakan tepung & $889,716,384.20$ \\
\hline 7 & $\begin{array}{l}\text { Melaksanakan proses pencampuran dan pengadukan tepung, air, dan } \\
\text { alkali }\end{array}$ & $783,746,910.39$ \\
\hline 9 & Melakukan proses pengepresan & $650,489,726.12$ \\
\hline 10 & Melakukan proses pengukusan & $642,220,216.17$ \\
\hline 11 & Melakukan proses penggorengan & $683,039,910.46$ \\
\hline 12 & Melakukan proses pendinginan & $625,767,497.52$ \\
\hline 13 & Perbaikan dan pemeliharaan mesin pengolahan & $883,649,467.93$ \\
\hline 14 & Pengecekan kelengkapan bumbu, minyak bumbu dan solid ingredient & $986,684,761.20$ \\
\hline & $\begin{array}{l}\text { Penyeleksian kelengkapan bumbu, minyak sauce dan solid ingredient } \\
\text { dengan menggunakan mesin rejector }\end{array}$ & \\
\hline 16 & Pengemasan/ Packing & $996,878,843.90$ \\
\hline 17 & Menyimpan barang jadi ke gudang khusus barang jadi & $9,364,998,629.92$ \\
\hline Total & & $100 \%$ \\
\hline & & \\
\hline Sumtase (\%) & \\
\hline
\end{tabular}

Sumber: Data diolah

Dari hasil tabel 4.6 dapat dilihat bahwa biaya overhead pabrik setelah mengalami pengeliminasian aktivitas tidak bernilai tambah adalah sebesar Rp 9,364,998,629.92 atau $20,30 \%$. 


\section{KESIMPULAN DAN SARAN}

\subsection{Kesimpulan}

Aktivitas-aktivitas tidak bernilai tambah yang terjadi pada PT. Indofood CBP Sukses Makmur, Tbk cabang Bitung yang dapat dihilangkan antara lain menyimpan tepung di gudang khusus tepung, pengecekan bumbu, minyak sauce dan solid ingredient dengan menggunakan mesin rejector, dan menyimpan barang jadi ke gudang khusus barang jadi. Dengan menerapkan ABM pada tahun 2016, maka penghematan yang seharusnya dapat dilakukan oleh pihak manajemen yaitu sebesar Rp 2,384,750,669.84 dan tercapainya efisiensi perusahaan dalam hal ini efisiensi biaya produksi yaitu sebesar $20,30 \%$.

\subsection{Saran}

Untuk dapat mencapai efisiensi biaya, maka pihak manajemen PT. Indofood CBP Sukses Makmur, Tbk cabang Bitung perlu meninjau kembali aktivitas-aktivitas produksi yang ada. Peninjauan tersebut dapat dilakukan dengan cara menerapkan ABM dalam operasi produksinya sehingga pihak manajemen dapat mengidentifikasikan aktivitas yang bernilai tambah dan aktivitas yang tidak bernilai tambah, karena aktivitas yang tidak bernilai tambah akan menimbulkan biaya tidak bernilai tambah. Menerapkan konsep ABM dengan cara:

1. Melakukan pembelian bahan baku pada saat persediaan bahan baku sudah mencapai titik pemesanan, agar perusahaan tidak mengalami kekurangan bahan baku ataupun kelebihan bahan baku.

2. Sebaiknya perusahaan memilih apakah dalam pengecekan bumbu, minayk sauce, dan solid ingredient dilakukan secara manual atau dengan mesin, sehingga tidak terjadi pemborosan biaya dan pengulangan aktivitas.

3. Menjaga kelancaran dalam penyaluran barang jadi dengan para distributor/ pelanggan, sehingga barang jadi dapat segera dikirim tanpa adanya penumpukkan barang jadi di gudang.

\section{DAFTAR PUSTAKA}

Atikson, dan Anthony A. 2011. Management Accounting. Buku Dua Edisi Pertama. Salemba Empat Jakarta

Fahmi, I. 2012. Manajemen Produksi dan Operasi. Edisi 1. ALFABETA. Bandung

Hansen, D.R dan Maryanne M. Mown. 2009. Akuntansi Manajerial Buku 1. Terjemahan oleh Denny Arnos Kwary. Edisi 8. Salemba Empat. Jakarta

Hansen, D.R, dan Maryanne M. Mowen. 2012. Manajemen Biaya. Salemba Empat. Jakarta. Blocher, E.J., dkk. 2011. Manajemen Biaya. Buku Satu. Terjemahan Susty Ambarriani Edisi Pertama. Salemba Empat. Jakarta.

Kalonio., Poputra., Tirayoh. 2017. Penerapan Manajemen Berbasis Aktivitas Untuk Meningkatkan Efisiensi Biaya Pada Whiz Prime Hotel Mega Mas Manado. Jurnal Riset Going Concern 12(2): 565-574. Universitas Sam Ratulangi Manado.

Mulyadi. 2013. Sistem Akuntansi. Edisi Keempat. Salemba Empat. Jakarta.

Sitorus., Poputra., Runtu. 2014. Penerapan Activity Based Management Untuk Meningkatkan Efisiensi Pada Hotel Sahid Kawanua Manado. Jurnal EMBA Vol.2(3): 1001-1009.

Siregar., Baldric., dkk. 2013. Akuntansi Manajemen. Jakarta: Salemba Empat.

Sugiyono. 2011. Metode Penelitian Kuantitatif Kualitatid dan R\&D. Penerbit Alfabeta. Bandung

Wirjono, E. 2013. Hubungan Antara Sistem Informasi Manajemen dan Ketidakpastian Lingkungan Yang Dirasakan Terhadap Kinerja Manajerial. Jurnal Ilmiah Akuntansi Dan Bisnis, Vol. 8(1) Fakultas Ekonomi. Universitas Atmajaya, Yogyakarta. 